\title{
Prevalence of Oral Mucosal Lesions in Geriatric Patients in Universitas Airlangga Dental Hospital
}

\author{
Fatma Yasmin Mahdani, Desiana Radithia, Adiastuti Endah Parmadiati and Diah Savitri Ernawati \\ Department of Oral Medicine, Faculty of Dental Medicine, Universitas Airlangga, Surabaya, Indonesia
}

\begin{abstract}
Background. Population aged 60 years old and above are growing in number; a fact that will have an impact on general and oral health in the future. Oral health is often overlooked in the management of geriatric patients but it is vital to have a knowledged-based practice in order to increase the quality of life of elderly patients.
\end{abstract}

Objective. The purpose of this study is to determine the number and types of oral mucosal lesions in geriatric patients who come to the Universitas Airlangga Dental Hospital.

Methods. This is an observational descriptive study with cross-sectional design. Intraoral soft tissue examination was performed on geriatric patients coming to the hospital between March and December 2018.

Results. One hundred twenty-four (124) new geriatric patients came to the hospital. A total of 152 oral lesions from 63 geriatric patients $(50.81 \%)$ were identified. Overall, coated tongue $(55.56 \%)$ was the most frequently detected lesion, followed by linea alba buccalis (31.74\%) and lingual varicosities (26.98\%).

Conclusion. Coated tongue or white tongue is the most frequently detected oral mucosal lesion, often caused by poor oral hygiene. The dentist should be able to recognize and differentiate them from the worrisome lesions and decide on the appropriate treatment in geriatric patients.

Key Words: oral mucosa, mouth diseases, geriatric dentistry

\section{INTRODUCTION}

According to the Government Regulation of the Republic of Indonesia Number 43 of 2004, an elderly person is someone who has reached the age of 60 years and over. Whereas according to World Health Organization (WHO), the elderly are 60-74 years old (elderly age), 7590 years old (old age), and more than 90 years old (very old). ${ }^{1-3}$ The elderly population in Indonesia is growing in number. In 2000, people who are older than 60 years old in Indonesia amounted to $14,396,745$ people. There was an increase in 2010 to $18,043,712$ people (Central Statistics Agency, 2012). Based on population projection data, it is estimated that the elderly population in 2025 will be 33.69 million (11.1\%), in 2030 a total of 40.95 million (12.9\%)

Paper presented at the Joint Scientific Meeting in Special Care Dentistry, July 5, 2019, Amerta Room, 4th Floor, main campus of Universitas Airlangga, Surabaya, Indonesia.

Corresponding author: Fatma Yasmin Mahdani

Department of Oral Medicine

Faculty of Dental Medicine

Universitas Airlangga

JI. Mayjen. Prof. Dr. Moestopo No. 47 Surabaya 60132 - Indonesia

Email: fatmayasminmahdani@fkg.unair.ac.id and in 2035 a total of 48.19 million. ${ }^{4}$

In the future, the size of the elderly population in Indonesia can have both positive and negative influences. Healthy, active and productive elderly residents have a positive influence. Whereas the elderly population becomes a burden most especially when experiencing a decline in health and income levels, an increase in disability, a lack of social support, and unfriendly environmental conditions. ${ }^{5,6}$ 

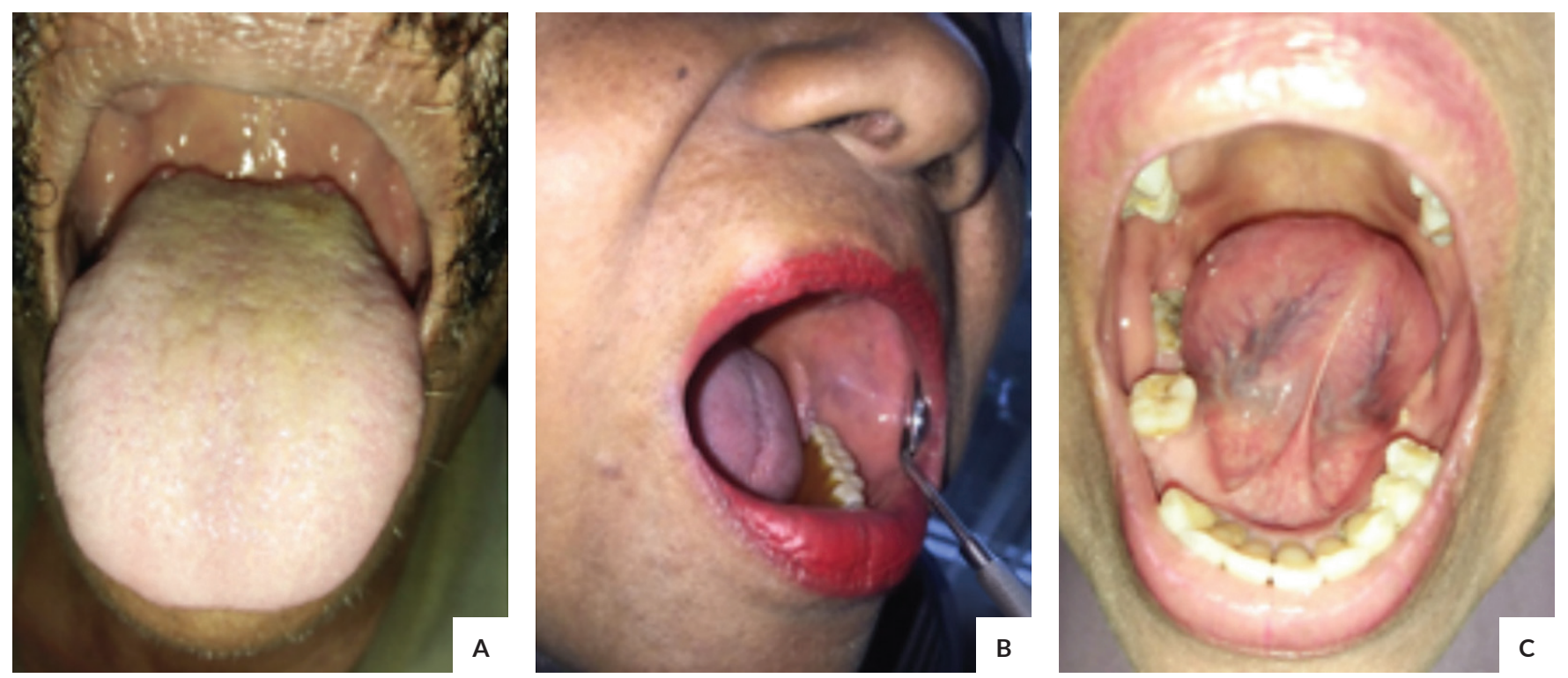

Figure 1. Intraoral clinical examination (A) coated tongue (B) linea alba buccalis and (C) lingual varicosities.

As age increases, so are the changes in a person's oral cavity. Mucosal function decrease so that it is prone to lesions in the oral cavity. The oral mucosa becomes less elastic due to a decrease in elastic fiber, pale, thin, dry, smooth, and reduced vascularity. The epithelium becomes more susceptible to mechanical injury and irritant agents. Vulnerability to microbes and fungal colonization of the epithelium increases with age. The physical and immunological defense of the mucous membrane is impaired, regenerative ability is reduced, and more susceptible to injury. ${ }^{5-7}$

The purpose of this study is to determine the number and types of oral mucosal lesions in geriatric patients who come to the Universitas Airlangga Dental Hospital, Surabaya, Indonesia. There is still a lack of reported data that is capable of projecting oral mucosal lesion in Indonesia, especially Surabaya as well as efforts to providing optimum service standards in geriatric patients. Therefore, this research can be a preliminary study in starting data collection about oral mucosal lesion in Surabaya. This research was conducted to serve as a guide in improving the oral health status of the elderly and improve life expectancy in elderly patients.

\section{MATERIALS AND METHODS}

This is an observational descriptive study with a crosssectional design. Ethics approval was obtained from the Universitas Airlangga Faculty of Dental Medicine Health Research Ethical Clearance Commission with registered number 475/HRECC.FODM/VII/2019.

Universitas Airlangga Dental Hospital is a public dental hospital in Surabaya, East Java, Indonesia. The present study was conducted on new patients who come to the Universitas Airlangga Dental Hospital, Surabaya, Indonesia between March and December 2018.
A screening examination including intraoral clinical examination was performed by an oral medicine specialist and a student from the oral medicine specialist program of the Department of Oral Medicine, Faculty of Dental Medicine, Universitas Airlangga. Personal data including age, gender, chief complaint, systemic condition, oral condition, and social habits were recorded. In this study, no investigation was carried out as well as routine examination, limited to only history taking (anamnesis) and clinical examination was performed. A working diagnosis of lesions was identified.

The obtained data were compiled and subjected to statistical analysis using Statistical Package for Social Sciences (SPSS) software version 25 (SSPS Inc., Chicago, IL, USA). Chi-square test was used to compare lesions with age and gender. Frequencies and percentages were calculated. $\mathrm{p}$-value $<0.05$ was considered statistically significant.

\section{RESULTS}

From March to December 2018, there were a total of $124(\mathrm{n}=6.03 \%)$ new geriatric patients screened at the Universitas Airlangga Dental Hospital. Age characteristic of the patients in this study is shown in Table 1 . Out of 124, 30 male geriatric patients $(\mathrm{n}=30 ; 24.20 \%)$ and 29 female geriatric patients $(\mathrm{n}=29 ; 26.61 \%)$ have oral lesions (Table 2).

A total of 152 lesions from 63 geriatric patients (50.81\%) were identified. Most common oral lesions in this study are coated tongue, followed by linea alba buccalis, lingual varicosities, fissured tongue, and torus. Frequency of oral mucosal lesions in geriatric patients is shown in Table 3. Most common oral lesions in this study are shown in Figure 1. Overall, there is no statistically significant difference in all oral lesions with age and gender $(\mathrm{p}$-value $<0.05)$. 
Table 1. Age characteristic of the patients in this study

\begin{tabular}{ccc}
\hline Age group & Patients screened & \% Patients screened \\
\hline 10 years & 120 & $5.84 \%$ \\
$11-20$ years & 289 & $14.06 \%$ \\
$21-30$ years & 777 & $37.79 \%$ \\
$31-40$ years & 277 & $13.47 \%$ \\
$41-50$ years & 261 & $12.69 \%$ \\
$51-60$ years & 208 & $10.12 \%$ \\
$\geq 60$ years & 124 & $6.03 \%$ \\
\hline
\end{tabular}

Table 2. Gender characteristic of the patients in this study

\begin{tabular}{ccc} 
Gender & Patients screened & Patients with lesions \\
Male & 60 & 30 \\
Female & 64 & 33 \\
\hline
\end{tabular}

Table 3. Frequency of oral mucosal lesions in geriatric patients Oral Mucosal Lesions Number of Patients Percentage Median Rhomboid Glossitis $1.59 \%$

Papilla Prominent

Smoker's melanosis

Bifid Tongue

Macroglossia or microglossia

Hairy Tongue

Fordyce's Spots

Ankyloglossia

Crenated Tongue

Morsicatio Buccarum

Exostosis

Hyperpigmentation

Ductus Stenson Prominent

Frictional Keratosis

Geographic Tongue

$1.59 \%$

$1.59 \%$

$3.17 \%$

$3.17 \%$

$3.17 \%$

$3.17 \%$

$4.76 \%$

$4.76 \%$

$4.76 \%$

$4.76 \%$

$6.35 \%$

$9.52 \%$

$9.52 \%$

$14.29 \%$

$25.40 \%$

$25.40 \%$

$26.98 \%$

$31.74 \%$

Linea Alba Buccalis $55.56 \%$

Coated Tongue

\section{DISCUSSION}

The oral cavity is a diagnostic indicator of various systemic diseases and truly mirrors the body. Sometimes the oral mucosa abnormality may be the first clinical evidence of a previously undiagnosed systemic condition, the early recognition, and treatment of which may modify the course or reduce the severity of the underlying disease, and thus render profound service to the patient. ${ }^{8,9}$ There is a lack of reported data that is capable of projecting oral mucosal lesion or abnormality in Indonesia, especially Surabaya as well as efforts to providing optimum service standards in geriatric patients. The faster the diagnosis of oral mucosal lesion is obtained, the faster the lesion is treated.

The role of oral medicine specialist is noteworthy for an appropriate diagnosis of various oral mucosal lesions, determining any underlying systemic disorder, detecting any malicious change at its earliest, referring for pertinent investigations, management, and most importantly education of the patient. Thus, the current study was done to determine the most common oral mucosal lesions in geriatric patients, use it as a guide in improving the oral health status of the elderly and providing optimum service standards such as awareness, knowledge, and treatment received.,6,10

Oral mucosa in a healthy elderly population is indistinguishable from another population. Changes over time, however, including mucosal trauma, mucosal diseases, oral habits, and salivary gland hypofunction can alter the clinical appearance and character of the oral tissues in elderly. Oral epithelium becomes thinner, loses elasticity, and atrophy. Decrease immunologic response increases the susceptibility to oral mucosal infection and trauma. The oral mucosa is a common site for various desquamative, ulcerative, and malignant lesions. The increased incidence of oral and systemic disorders in older patients along with the increased use of medications can also lead to oral mucosal disorders. Both normal aging changes and pathologic factors can contribute to oral lesions. ${ }^{5-7}$

Most common oral mucosal lesions in this study was coated tongue (55.6\%). A study in nursing homes in Surabaya and Yogyakarta reported that the most common oral mucosal lesion was fissured tongue (64.9\% and 51\%, respectively), while the fissured tongue was found to be the fourth most common lesion in this study. A study in a geriatric Indian population reported that the most common oral mucosal lesion was smoker's palate and melanosis (64\%) which was associated with tobacco and betel nut consumption. ${ }^{11-13}$

Coated tongue or white tongue is one of the normal variants of the tongue, comprising of anaerobic bacteria, large amounts of desquamated epithelial cells, leukocytes from periodontal pockets, blood metabolites, and different nutrients, and sometimes inflamed papillae. An untreated coated tongue can be a good medium for bacteria and another microorganism. Enforcement of the diagnosis of coated tongue is from clinical examination, which is obtained by white pseudomembranous on the dorsum of the tongue and can be scraped but does not cause pain and erythematous area. One of differential diagnosis of coated tongue is oral thrush. Coated tongue was considered an ideal atmosphere to produce malodorous compounds which includes hydrogen sulfide, methyl mercaptan, and dimethyl sulfide, therefore, establishing the relationship between tongue coating and halitosis. Therefore, coated tongue must be treated appropriately in geriatric patients in order to increase patient confidence and life expectancy. ${ }^{8,9,14}$

Linea alba buccalis is a common intraoral finding which appears as a raised white wavy line of variable length and prominence. It is located at the level of the occlusion on the buccal mucosa. Generally, the linea alba buccalis is asymptomatic, 1 to $2 \mathrm{~mm}$ wide, and extends horizontally from the second molar to the canine region of the buccal 
mucosa, ending at the caliculus angularis. Linea alba buccalis develops as a response to frictional activity of the teeth, which results in thickened (hyperkeratotic) epithelial changes. The condition is often associated with crenated tongue and may be a sign of pressure, bruxism, clenching, or sucking trauma. Enforcement of the diagnosis of linea alba buccalis is from clinical examination and no treatment is required. ${ }^{10,15}$

Lingual varicosities or phlebectasia was enlarged dilated veins on the ventral surface of the tongue, are a common finding in elderly adults. Lingual varicosities were caused by vascular dilatations either a blockage of the vein by an internal foreign body, such as an atherosclerotic plaque, or the loss of elasticity of the vascular wall as a result of aging. Intraoral varicosities most commonly appear superficially on the ventral surface of the anterior two-thirds of the tongue and may extend onto the lateral border and floor of the mouth. Men and women are affected equally. Enforcement of the diagnosis of lingual varicosities is from clinical examination, which appears as red-blue to purple fluctuant papules or nodules. Individual varices may be prominent and tortuous or small and punctate. Palpation does not elicit pain but can move the blood temporarily out of the vessel, thereby flattening the surface appearance. Diascopy test was needed to enforce diagnosis of lingual varicosities by pressing against the lesion with a clear plastic tube or glass slide and causes varices to blanch. ${ }^{9,10,15,16}$

Fissured tongue is one of the normal variants of the tongue that can consist of a single midline fissure, double fissures, or multiple fissures of the anterior two-thirds of the dorsum surface of the tongue. The cause of fissured tongue is unknown, but it often develops with increasing age and in patients who have hyposalivation. Fissured tongue may become secondarily inflamed and cause halitosis like a coated tongue, as a result of food impaction. Brushing the tongue to keep the fissures clean is recommended., ${ }^{914-16}$

Torus is a bony exostosis (outgrowth) located in the midline of the hard palate posterior to the bicuspid teeth called torus palatinus and in the lingual of mandibular gingiva called torus mandibularis. Torus supposed growth in geriatric patients because the cortex thins and porosity increases from about $4 \%$ to $10 \%$ from age of $40-80$ years old. Enforcement of the diagnosis of torus is from clinical examination and no treatment is required. ${ }^{9,15}$

This study is expected to be used as a guide in improving the oral health status of the elderly and providing optimum service standards in geriatric patients. Oral disease prevention is still the central focus for the geriatric patients as for other patient populations. Geriatric patients have various functional and behavioral changes that require special consideration during dental treatment and oral hygiene education. Communication between dentist and patient very often needs to be enhanced so that the patient gleans the most out of both the treatment and the instruction. Regardless of dentition status, it is recommended that the geriatric patients make dental visits at least every six months for clinical re-evaluation and depending upon the ability to perform oral hygiene for prophylaxis. Since denture-related and other oral mucosal lesions are common in geriatric patients, edentulous patients should be periodically evaluated by dental professionals. ${ }^{3,5,6,17}$ This study is expected to be a preliminary study and developed more deeply covering age, gender, dentition status, deleterious habits, and medical and pharmacological history.

\section{CONCLUSION}

Most common oral lesions in this study are coated tongue, followed by linea alba buccalis, and lingual varicosities. Coated tongue or white tongue is caused by poor oral hygiene. The dentist should be able to recognize and differentiate them from the worrisome lesions, and decide on the appropriate treatment in geriatric patients. Oral disease prevention is still the central focus for the geriatric patients and increasing oral hygiene can improve the health status of the geriatric patient's oral cavity and providing optimum service standards.

\section{Acknowledgment}

The authors thank the Department of Oral Medicine, Faculty of Dental Medicine, Universitas Airlangga and Universitas Airlangga Dental Hospital, Surabaya, Indonesia.

\section{Statement of Authorship}

All authors participated in data collection and analysis, and approved the final version submitted.

\section{Author Disclosure}

All authors declared no conflict of interest.

\section{Funding Source}

None.

\section{REFERENCES}

1. Orimo H, Ito H, Suzuki T, Araki A, Hosoi T, Sawabe M. Reviewing the definition of "elderly". Geriatr Gerontol Int. 2006; 6(3):149-58.

2. Government Regulation of the Republic of Indonesia. Government Regulation of the Republic of Indonesia Number 43 of 2004 about Implementation of Social Welfare in Elderly [Internet]. 2004 [cited 2019 April]. Available from: https://peraturan.bpk.go.id/Home/ Details/66188

3. World Health Organization. World Report on Ageing and Health [Internet]. Luxembourg; 2015 [cited 2019 April]. Available from: https://apps.who.int/iris/bitstream/handle/10665/186463/ 9789240694811_eng.pdf;jsessionid=BD93BF25ABA483D0ACAA 5E434AAE6496? sequence $=1$

4. Indonesia Central Statistic Agency. Population in Indonesia [Internet]. [cited 2019 April]. Available from: https://www.bps.go.id/ dynamictable/2018/03/20/1288/persentase-penduduk-menurutprovinsi-dan-jenis-kelamin-2009-2018.html

5. Ghom A, Ghom SA Textbook of Oral Medicine, 3rd ed. New Delhi: Jaypee Brothers Medical Publishers (P) Ltd; 2014. pp 501-514; 1030-1032.

6. Glick M. Burket's Oral Medicine, 12th ed. Shelton, Connecticut: People's Medical Publishing House; 2015. pp 653-657. 
7. Kaminska-Pikiewicz K, Chalas R, Bachanek T. The condition of oral mucosa in the elderly (over 65 years) of Lublin. Curr Issues Pharm Med Sci. 2017; 30(1):39-42.

8. Bhattacharya PT, Sinha R, Pal S. Prevalence and subjective knowledge of tongue lesions in an Indian population. J Oral Biol Craniofacial Res. Craniofacial Research Foundation; 2016 May-Aug; 6(2):124-8.

9. Ali M, Joseph B, Sundaram D. Prevalence of oral mucosal lesions in patients of the Kuwait University Dental Center. Saudi Dent J. 2013; 25(3):111-8.

10. Odell E. Cawson's Essentials of Oral Pathology and Oral Medicine, 9th ed. Elsevier Ltd.; 2017. pp 283-284.

11. Endah A, Ernawati DS, Subiakto BDS. Prevalence of oral cavity soft tissue abnormalities in elderly at Panti Surya and Hargodedali Surabaya in August-September 2014. Oral Medicine Dental Journal. 2015; 7(1):72-7.

12. Patil S, Doni B, Maheshwari S. Prevalence and Distribution of Oral Mucosal Lesions in a Geriatric Indian Population. Can Geriatr J. 2015 Mar;18(1):11-4.
13. Agustina D. Oral hygiene and number of oral mucosal lesion correlate with oral health-related quality of life in elderly communities. Dental Journal (Majalah Kedokteran Gigi) 2014;47(1):57-61.

14. Mangold AR, Torgerson RR, Rogers RS. Diseases of the tongue. Clin Dermatol. 2016 Jul-Aug; 34(4):458-69.

15. Langlais RP, Miller CS, Gehrig JS. Color Atlas of Common Oral Diseases, 5th ed. Philadelpia: Wolters Kluwer; 2017. pp. 126-130; 152-154.

16. Madani FM, Kuperstein AS. Normal variations of oral anatomy and common oral soft tissue lesions: evaluation and management. Med Clin North Am. 2014 Nov; 98(6):1281-98.

17. Lockhart PB. Oral Medicine and Medically Complex Patients, 6th ed. Iowa: Wiley-Blackwell; 2013. pp. 151-157. 